\title{
ITS-Based Transport Concepts and Location Preference: Will ITS Change 'Business as Usual’?
}

\author{
Chapter · December 2007
}

DOI: $10.1007 / 978-3-7908-1765-2-17$

CITATION

1

3 authors, including:

\section{Robert van der Heijden}

Radboud University

94 PUBLICATIONS 725 CITATIONS

SEE PROFILE
READS

40

Vincent Marchau

Delft University Of Technology \& Radboud U... 47 PUBLICATIONS 248 CITATIONS

SEE PROFILE 


\title{
ITS-based transport concepts and locational preference: Will ITS change 'business as usual'?
}

\author{
Raffael Argiolu* ${ }^{*}$ Rob van der Heijden, ${ }^{1,2}$ Vincent Marchau ${ }^{2}$ \\ ${ }^{1}$ Group of Urban and Regional Planning, Nijmegen School of Management, Nijmegen University, PO Box 9108, \\ 6500 HK Nijmegen, The Netherlands, \\ ${ }^{2}$ Group of Transport Policy And Logistics' Organisation, Delft University of Technology, Delft, The \\ Netherlands
}

\begin{abstract}
Intelligent Transportation Systems (ITS) are expected to solve problems regarding safety, congestion and environmental issues. Currently, automotive industries develop many applications, which are implemented in car driving, freight transportation and public transport. Our theory is based on the assumption that especially further integration of Advanced Driver Assistance Systems (ADAS) and travel based Information and Communication Systems (ICT) results in new and more attractive ITS concepts. These concepts will influence the performance of both passenger and goods transportation. Consequently, these integrated ITS concepts might in the long run influence the spatial dynamics and more specifically the development of firm locations. To test this hypothesis we use a systemic approach of scenario building. The construction and validation of these scenarios must result in both plausible and attractive images of future ITS. We need these images to conduct a survey and test our hypothesis. The scenarios will provide different futures of an urban region, with differences in accessibility and image of the transportation system. Besides the reaction of firms, we are also interested in responses of actors that develop locations, so-called suppliers. Both suppliers of and demanders for locations create our future space.
\end{abstract}

Keywords: Intelligent Transportation Systems; Firm location development; Research design

\section{Introduction}

The development of Intelligent Transport Systems (ITS) has taken a leap in the past decade. Under strong influence of improved Information and Communication Technology (ICT) industries, automotive suppliers and scientific institutes have put much effort on developing a range of ICT based applications for vehicles to drive safer, more comfortable, to make more efficient use of current and future infrastructure and to manage fleets more accurately. Policymakers show increasing interest in ITS as a tool for solving traffic and transport problems facing society (e.g. congestion, environmental damage and traffic safety). This interest of policymakers is backed by findings of preliminary scientific research which show that promising perspectives seem within reach (Marchau \& Van der Heijden,

\footnotetext{
${ }^{*}$ Tel.: +31 24 3613056; fax: + 31243611841

E-mail first author: r.argiolu@nsm.kun.nl
}

2003). 'ITS is different from transportation advancements that it promises to increase the system's throughput substantially [...] (Tayyaran \& Kahn, 2003: 91). However, with respect to ITS policymaking many uncertainties exist regarding for instance real traffic impacts of ITS (drivers might adapt their behaviour) and conditions for implementation (e.g. acceptance among users, liability in case of malfunctioning devices), legal issues (Van der Heijden \& Van Wees, 2001) and safety potentials (see e.g. Hegeman, forthcoming). Hence, on the short term, the way in which ITS will affect traffic and transport system performance is still everything but sure. Although throughout the past years more and more knowledge is gained on the validity of intended ITS impacts and conditions for implementation, there is still a lot of work to be done in this area. 
In addition, the long-term effect of ITS on spatial dynamics is even more uncertain. Despite this uncertainty, the expectation that ITS concepts will, in the long term, have significant spatial effects on the location pattern of, in particular firms, is plausible. We can conclude from history that innovations in transportation systems have had significant influence on spatial patterns of activities (see e.g. Filarski, 1999). In general, distances between activities like for example residing and working have increased. Although some patterns of development are clear and can be explained easily, the nature of the relation between new transportation services and infrastructure and spatial patterns of locational development remains difficult to make explicit (see e.g. Banister, 1995). Therefore, we have to develop hypotheses on these relationships with regard to the introduction of ITS. First, we assume that the implementation of ITS will change the preferences of actors regarding locations of companies. Secondly, we assume that if preferences will change, they follow the pattern of ITS implementation. The theoretical background and the methodological exploration to research these hypotheses are described in this paper.

In doing so we need more insight in the possible role of ITS in location theory. Why do locations emerge at a certain spot and not elsewhere? Is there any difference in preferences between companies ${ }^{1}$ ? How important are preferences of companies? How influential is supply of locations? What role do municipalities play? Which ITS are considered to be so attractive? Have researchers already gathered some empirical evidence? How can we study the role of ITS in location development of firms? Can we learn from practice? Or do we need more explorative research methods? These questions, and others, are part of our puzzle and will be discussed in this paper. The contribution of this paper is threefold.

\footnotetext{
${ }^{1}$ Although we do not make this explicit we are aware of the fact that it is not 'companies' as such that make judgments and corresponding decisions on (re)locations but locations preferences actually depend on the decision making process within the company. For more on decision making processes within relocating companies see e.g. Pen (2002: 52 91).
}

First, section 2 briefly discusses the link between transportation and location development. During the $20^{\text {th }}$ century the importance of transportation development as an explaining variable, within location theory has changed. Its importance has decreased while other factors have become more important. Still, it is assumed that the attractiveness (nearness and quality) of the transportation system has an important influence on location preferences. The attractiveness of a transportation system is dependent on the perception on the travel time, comfort, reliability and other elements of service. In most studies conducted on stated preferences of companies regarding locational alternatives, companies refer to the importance of accessibility, proximity and image. In contrast to research that focuses on current location preferences of companies; our future exploration also takes into account the preferences of suppliers of locations. Municipalities and real estate developers play an important role in developing new locations. So if we want to know how whether ITS contributes to the attractiveness of a transportation system and as a consequence influences location preferences, we have to study its perceived gains as compared to other variables influencing attractiveness.

Section 3 subsequently explores the nature of future ITS, which is plausible in being so attractive. ITS systems cover, among others, systems that support the driver in controlling his/her vehicle in a better way (Advanced Driver Assistance Systems (ADAS), systems that support the traveller in finding an optimal mode and route, (Advance Traveller Information Systems (ATIS) and systems that are concerned with a more efficient organisation of traffic flows throughout the existing road infrastructure network (Advanced Traffic Management Systems = ATMS). We argue that most potential to reach a higher service level in transportation is expected from integration between ADAS and ATMS and ATIS. Further, integration seems very appealing in terms of safety benefits, throughput in networks and environmental issues (Van der Heijden \& Marchau, 2002). However, in practice integration of ADAS, ATIS and ATMS systems hardly occurs and therefore has not resulted in many new ITS modes. 
Section 4 proposes a combination of methods to explore the influence of ITS on the development of firm location. An attractive way of studying these future impacts of ITS is by means of scenarios. ITS scenarios are first constructed based on existing cases and relevant knowledge, as described in literature. These scenarios are next assessed on their feasibility and likeliness in order to come up with set of so called plausible scenarios. These plausible scenarios will be used in our future research in a survey among actors that are involved in the location development of firms.

\section{Theorizing preferences regarding business locations}

The motives that firms have for (re)locating have been a scientific issue since 200 years approximately and can be summarized by socalled (re)location theories. Pellenbarg et al. (2002) distinguish three approaches of (re)location theories: the neo-classical, the behavioural, and the institutional approach. These could be extended with a fourth, namely: the 'classic' theories.

These older 'classic' theories, as described by Von Thünen $(1826)^{2}$ and Weber $(1906)^{3}$, presumed landlords (in the case of Von Thünen) and industrial companies (in the case of Weber) behaving as a 'homo economicus', which characteristic was totally formed by maximising profit. Transportation costs were considered as very important variables in this maximization (see note 2 below). Later, these classic theories were elaborated by neo-classic location theories, with several changes in the assumptions, for

\footnotetext{
2 Von Thünen, presented a theory, in which a agricultural business man, who strives for maximization of profits (W), must realise an optimal difference between the given market price (VM) and the sum of production $(\mathrm{P})$ and transport costs $(\mathrm{T})$. In formula: $\mathrm{W}=\mathrm{VM}-(\mathrm{P}+\mathrm{T})$.

${ }^{3}$ Webers' theory (1909) focussed on the location of industrial businesses. Therefore, he addressed other location factors than Von Thünen did (see Von Thünen, 1826). He called those factors 'standortfaktoren'. Webers' theory agued that minimization of transportation costs of raw materials (which are site specific, the 'Lokalisiertes Material') was the impetus for businesses to locate. He also addressed the importance of labour costs (1909).
}

instance from perfect to imperfect competition (see e.g. Hoteling, 1929). Despite the differences, both classic and neo-classic theories considered transportation costs as an important settlement factor for firms. The emphasis on costs and profit shifted away when so-called 'behaviourists' introduced the notion of the 'homo psychologicus' (see e.g. Simon, 1957; 1960). People were now assumed to behave as 'satisficers', instead of 'optimisers'. The notion of 'bounded rationality' was introduced. The behaviour of firms was regarded similarly. This meant that they would accept certain limitations in their choice. This also accounted for choices regarding locations. In the decision making process, firms had to cope with uncertainties and incomplete knowledge. These 'behavioural' theories where further elaborated with notions as the construction of mental maps, spatial cognition and regional image. The notion of spatial cognition can best be explained as: 'knowledge of spatial entities and consequently of possible locations' (Lambooy et al., 1997, translation ours). Spatial cognition is regarded as the bases on which locations are valued. This leads to the other two notions mentioned: mental map and regional image. The former is the image of certain locations or regions. Regional image has a somewhat broader definition, which also contains an element of pre-judgement, personal correct or incorrect information and stereotypes. An example is that people regard Paris as the 'city of romance' and perceive the Ruhr area in Germany as 'dirty'.

Other than the former three approaches, institutional approaches do not only look at the firm, but also consider the social and cultural context in which this behaviour is embedded. This view is based on the idea that firms have to negotiate with deliverers and suppliers, local, regional or national governments, labour unions and other institutions, about prices, wages, taxes, subsidies, infrastructure, and other key factors in the production process of the firm. Locational behaviour is the result of the outcome of these negotiations (Pellenbarg et al., 2002). Because of a risen complexity and less belief in deductive approaches, more research has focussed on empirical data. Characteristic about these data is the aim to explain location development according to preferences or so-called settlement factors. 


\begin{tabular}{ll}
\hline & General location preferences \\
\hline 'Stationeries' & Organisations with a strong preference for locations near pubic transport facilities. \\
& Other important factors are: working conditions, such as a nice atmosphere, flexibility \\
& within the interior design and organization of the building and accessibility of the \\
& entree. Representation is of less importance. This group consists of governmental and \\
& non-profit organisations. \\
'Modals' need common buildings with standard facilities. Accessibility by car and the \\
presence of parking lots are important. There is no need for a representative building, \\
and the proximity of public transport is even less important, whereas the rent price \\
should be as low as possible. Core activities of this group are mainly non-office \\
companies like industries, trade companies and transport organisations. \\
'Visuals' consider representation and aesthetics very important. Further, the company \\
name or logo needs a prominent position on the outer wall. The image of the building \\
has to be congruent with its own product. 'Visuals' are willing to pay relatively high \\
rents. Commercial organisations, service businesses, banks and insurance companies \\
are considered as visuals. \\
'Most important location factor for ambulatories is accessibility by car. This group \\
provides its services predominantly outside the building, with the building as base. \\
Representation is of less importance as most of the clients are spread throughout the \\
country. Ambulatories are mostly smaller businesses (less than 20 employees) in the \\
services sector: banks and insurance businesses. \\
These users prefer settlements characterised by historical and dignified milieus. They \\
opt for traditional buildings. They settle in city centres and accept less accessibility by \\
car. This group consists of law firms, accountant offices, notaries, brokerages and \\
some governmental institutes, like embassies, for whom representation is of less \\
importance
\end{tabular}

To predict or explain movement of companies, various stated preference surveys have been conducted. Although some results differ, little change seems to have occurred in the last decades regarding the nature of these locationor so-called settlement factors in the Netherlands. Lukkes et al. (1987) described four factors of increasing importance: accessibility, representation, proximity of clients and the quality of the building in comparison with the price.

Later, Atzema \& Wever (1994) note that lack of accessibility plays an important role as a push-motive ${ }^{4}$ for companies. Further, accessibility was the most important pullfactor $^{5}$, which included proximity to clients, suppliers, local unlocking and parking lots. More recently, Pellenbarg et al. (2002) emphasise the work of Louw (1996); he found that the most important motive to leave a location is the fact that a firm has not enough space to expand.

In latter stages of the decision making process to relocate, location specific features, like for example accessibility and

\footnotetext{
${ }^{4}$ Push-motives are reasons to move from a location. An example is the lack of space to expand.

${ }^{5}$ Pull-factors are reasons that relate to a new location. An example is an ideal accessibility in the new situation.
}

representation, become increasingly important. The last stages are characterised by negotiations about prices of location and parking space. As described, companies prefer multiple settlement factors. Furthermore, the emphasis on the specific factors is influenced by the differences in the nature of companies. Table 1, which is based on an overview described by Louw $^{6}$ (1996), is a typology based on this distinction. According to this table 'stationeries' are considered to be more interested in public transport facilities than for instance 'modals' are. Companies that are mainly attracted by representation and aesthetics are regarded as 'visuals'. Embassies, account offices and universities can be seen as 'classicists'. They prefer settlements characterised by historical and dignified milieus.

Louw (1996) criticizes this typology for three reasons: a decrease in importance of the settlement factors does not mean that the explanatory function also decreases. Spatial differences can be described to settlements factors that are considered to be less important. The second criticism of Louw (1996) is that preferences of companies do not account for the supply side which influences spatial

\footnotetext{
${ }^{6}$ The table is based on research performed by the Dutch real estate company DTZ Zadelhoff
} 
outcomes too. The third critique is that such a distinction does not include the combinations in decision-making or the internal relations. We would like to add another point of critique, which is based on the topic of this paper. If we want to study location development and spatial differences, we are mainly focussed at spatial impact. And spatial impact is also based on the size of the companies and the 'spatial' life cycle $^{7}$ of companies.

It is clear that most of the location theory has changed in three major steps and has become more sophisticated than the oldest classic theories. At first current research uses an institutional approach and also considers the social and cultural context; the idea that firms have to negotiate with a multitude of actors, about prices, wages, taxes, subsidies, infrastructure, and other key factors in the production process of the firm. This approach is miles away from the first classic theories that explained location by a simple formula. Another improvement concerns the distinction between the nature of the company and the differences in location preferences. A third theoretical elaboration is aimed at the removal process of companies. The importance and relevance of settlement preferences seem to correlate with different stages in the process of moving from location $a$ to location $b$. In accordance to this removal process is a fourth aspect which is described in the next paragraph: location development as a result of matching between demand and supply.

\subsection{Location development, matching supply and demand}

According to Louw (1996) there are three theoretical gaps in location theory: the neglect of market processes, the neglect of the relation between location factors and business removal, and the overemphasis in literature on economic processes and its influence on spatial structures. This has resulted in an 'overemphasis on the demand side of the urban system: the location preferences of firms and households are held responsible for urban development' (Van der Krabben \& Lambooy,

\footnotetext{
${ }^{7}$ Similar to products also companies have a life cycle. The motive to move from one location to another is strongly related to the stage of the company in the cycle.
}

1993: 1382). Locational development cannot merely be explained by demands of companies. A description of locational development should also account of the spatial development policy, especially in the Netherlands with its active land policies. These policies involve the land market. Although the nature of the Dutch spatial development policy is changing (see e.g. Louw et al., 2003), a focus on the explanation of the why's and who's of firm location development should include more preferences than only those of firms. Pen (2002) already shows that 'external actors' like for example architects and accountants play an important role in the relocation process of companies. Irrespective of this involvement, we think that some of these 'external actors', for example real estate developers and municipalities are also involved in the development of new location sites, without knowledge of the specific companies it will accommodate.

An exploration on the influence of ITS on locational development of firms should aim at more actors than companies solely. It should also focus on actors as for example municipalities that both influence land usage and infrastructure development. Their statement on the importance of an ITS scenario on location preferences is therefore very important.

Louw concludes that 'considering the fact that suppliers of office space make location choices in their new estate plans, they are full actors in the field of force of actors that influence the spatial dispersion of office companies' (1996: 204, translation ours). Moreover it is very likely that actors involved in the development of an ITS concept would use any tool, in this case for example an urban development project, to make a technological advanced ITS project, successful.

Suppliers of business locations (e.g. municipalities and real estate developers) create themselves images on the level of accessibility required by the potential companies locating in these zones. For example, Bok et al. (2003) show that especially firms in the public sector tend to follow the Dutch ABC-location-policy and move towards a-locations. a-Locations are typified by Bok et al. (2003) as locations with a distance to an intercity station less then 800 meters. Further, it seems for instance that 'location policies' of municipalities in the 
Netherlands, although not anymore explicitly driven by the national government ${ }^{8}$, focus implicitly on the proximity of transportation systems. This could be explained as a result of a process policy-making (see e.g. Parsons, 1999). We assume that the development or renewal of an important (in other words: expensive) public transportation systems, such as ITS, is likely to become an issue for policy making (e.g. Marchau and Van der Heijden, 1998). If so, other policies like spatial development could become seriously influenced by that.

The assumption that actors such as municipalities could combine the interest in for example public transport ITS and the development of nearby firms locations is supported by research (see e.g. Edwards \& Mackett, 1996). After studying 11 new public transport systems in the UK they distinguished two objectives of constructing the transport system. The reasons were generally either transport issues or economic and development issues. A major reason for many systems was to stimulate economic and thus spatial development. Although there is little evidence that building new public transport systems does stimulate such a development, "it is more likely to do so if a comprehensive plan is being followed or if complementary means of encouraging development are used' (Edwards \& Mackett, 1996: 229). What should be noted is that governmental bodies perceive only those public transport systems, which have fixed infrastructure, to attract developers and users of areas near the public transport systems (Edwards \& Mackett, 1996).

If we look at new public transport systems and spatial development plans in the Netherlands similarities are not difficult to find. Since technology seems to have a special role in decision making processes and dedicated transport systems and spatial development plans are often linked, this research should study on preferences of actors

\footnotetext{
${ }^{8}$ The Fourth Report on Physical Planning Extra (VINEX, 1991: 16-20) formulated an ABC-location policy. A-locations were situated next to road infrastructure, B-locations next to road infrastructure and public transportation and Clocations only next to public transportation. Later in the nineties, the policy was stopped, due to poor results.
}

both at the demand and the supply side of business area developments.

\section{Unfolding 'attractiveness' of ITS}

In the previous sections we have explained the main part of the theoretical framework. What is not explained yet is what it is in ITS that would influence location development. Considering the theoretical part of section 2 it is expected that ITS influences locational development if it changes the nature of one of the settlement factors of a location. It speaks for itself that if ITS influences any settlement factor it would be accessibility and/or the image of a location. We define the extent to what ITS can increase the accessibility and/or image of a location as the attractiveness of a transportation system. Related to accessibility is the proximity of relevant services to a location.

Before discussing the nature of ITS, we have to explore the meaning of attractiveness of a transportation system. According to our preliminary definition attractiveness has to do with the extent to which the transportation system is capable of increasing the service level in travel. At its turn, this is strongly related to what is often called 'accessibility'. Accessibility is 'the number of persons/households per transportation system per class of movement resistance to the business location in relation to other, similar, locations, as perceived by an actor involved in the development of business locations' ${ }^{9}$. This definition needs some explanation.

First, a business location is a zone where, according to the land use plan, businesses are settled or allowed to settle. Secondly, a transportation system is a means to accommodate a geographical transport of information, freight or passengers. At least infrastructure and vehicles are important elements of the transportation system (in case of physical transportation). Thirdly, the notion of 'movement resistance' refers to the effort to move information, goods or persons from one geographical position to another. This effort can for example be measured by time, costs, distance and comfort. The importance of the

\footnotetext{
${ }^{9}$ Partly based on the definition of Hakkesteegt (1991: 4.7:)
} 
applied indicator is dependent on what is transported. For instance, the travel distance does not matter for the transportation of information. In that case, speed and costs matter. For freight transport costs and time have become dominant for measuring movement resistance (Muilerman, 2001; Runhaar, 2002). In passenger transport comfort, trip duration and travel time reliability have become increasingly important. Hence, distance as such has become less important as compared to the past. The fourth element to be explained is the phrase: 'in relation to other, similar, locations..'. Measuring accessibility of a zone in absolute terms has limited informative value, since the valuation (and influence on decision making of firms and households) is always related to and dependent on the accessibility of other locations within the search area. The fifth element is that a valuation of accessibility is always dependent upon the perception of accessibility because '[...] there is no such thing as unmediated data or facts: these are always the results of interpretation' (Alvesson \& Sköldberg, 2000: 9). Hence, there is no such thing as 'absolute' accessibility.

The perception of accessibility could be seen as a construction of two important elements: by 'tangible' and 'less-tangible' elements of accessibility. To explain 'tangible' accessibility we use another definition of accessibility. Hakkesteegt (1986) defines accessibility as 'the possibility that activity spaces can be used by individuals within stated budgets of time, costs and discomfort' (Hakkesteegt, 1986: 3.4). This implies that for instance ITS can contribute to accessibility if it supports faster, cheaper and more comfortable transport. Such a measurement would describe effects in hard numbers, which leave little room for interpretation. Such an interpretation would only differ from the approach which was used to describe accessibility. Geurs and Ritsema van Eck (2001) distinguish different measurements to describe accessibility. One difference for example is between activity based accessibility and infrastructure based accessibility. Infrastructure based accessibility measures do not incorporate a land-use component, in contrast to activity based. This can lead to different conclusions and consequently different perceptions. For example, in the Netherlands, employment is concentrated in the highly urbanised western part of the Netherlands (The Randstad). In this area, the main road network is heavily congested during peak hours. 'From an infrastructure-based accessibility measure as 'average speed on the main road network', one may conclude that the level of accessibility in the Netherlands is lowest in the Randstad, whereas from an activity- based accessibility measure (e.g. the number of jobs within 45 minutes travel time by car) one may conclude that the Randstad area shows the highest level of job accessibility of the Netherlands, despite the higher average travel times as a result of congestion' (Geurs \& Ritsema van Eck, 2001: 21). So even if tangible data is at forehand it could easily be misinterpreted by for example companies.

The second important element of attractiveness is the perception on less-tangible data. Less-tangible features of a transportation system are less easy to measure. Examples of 'less-tangible' factors are, trust, reliability or flexibility of transport facilities. The valuation of accessibility impacts of for example ITS should reckon with both aspects.

We distinguish a second possible element that could increase the attractiveness of a transportation system in relationship to locations: image. Image is related to those features of a transportation system that does not involve the travel based services. For instance the design of the transportation system could be of a high standard. Further it is possible that innovations in transportation help creating a more positive image of the system. For example, firms could regard a technologically advanced transportation system as a signal that the location is settled within an innovative region.

Although we suggest to study the influence on the attractiveness of ITS regarding a location, it remains difficult to separate the influence of one variable, namely attractiveness of a transportation system, from the influence of other factors on the decision to (re)locate. Over time, several surveys have been conducted in the Netherlands to gain understanding about the role of the different settlement factors. However, they do not show a clear pattern. In their first empirical exploration on the importance of accessibility in migration patterns of firms, Bok et al. for instance find that 'accessibility appears to express itself in the migration pattern of firms significantly at different scale levels but further 
research is necessary to determine the exact relationship' (2003: 15). So, it seems that accessibility is indeed very important, but it is not clear to what extent changes in accessibility can be decisive in case of a (re)location of a company. Some companies might focus more on for instance the quality of the building and its immediate environment, whereas others see 'good access' as a 'status determinant'. For instance: 'Some firms want to be located near an international airport or a high quality public transport terminal, whether or not the employees, costumers or clients regularly us these travel modes' (Geurs \& Ritsema van Eck, 2001: 93). Bok et al. (2003) conclude that firms in business services and finance display concentration patterns: it is observed that these firms move to locations with a larger number of jobs nearby. These are often peripheral locations that are accessible by car and closer to onramps but in general with worse public transport and with a less good accessibility for residents or employees. In contrast, government departments show a location pattern which is much more oriented to the city centre: closer to intercity stations and more jobs and inhabitants within reach of 15 minutes from new locations (Bok et al., 2003).

In short, the theoretical framework contains two main difficulties. The first difficulty lies in the theoretical assumptions on location theory. In most studies location development is totally explained by stated preferences of companies. However, this seems to be inadequate since location development is also dependent upon the supply of locations (Louw, 1996). For example, in scenario-building it is argued that active land policies, seen as a 'supply-oriented' approach, result in different locational development than approaches that are more influenced by demanders preferences, which are so-called 'demand oriented' approaches (Geurs \& Ritsema van Eck, 2001). Our study aims to reckon with this complexity. Secondly, it is still rather unclear how important the attractiveness of the transport system is relative to other settlement factors. The importance seems to vary with the type of company. Thus considering both difficulties, in the methodological exploration we will also focus on the relative importance of ITS attractiveness on parties involved in the supply side. And what is the nature of the ITS that is considered to be so important?

\section{Location development, the link with ITS}

In the previous section, we discussed a hypothetical relation between ITS and the (re)location of firms. We also mentioned that there is no large scale implementation of infrastructure based ITS within our reach at present to test our hypotheses in practice. Therefore, we have to follow another research strategy.

First, in this section, ITS systems are specified that are assumed to contribute to attractiveness and influence different actors involved in the location development process. We will discuss plausible images of large scale implementation of ITS in an urban region. One could say why at the level of the region? One important reason for looking at the urban region is that this seems the appropriate environment for which ITS will be implemented initially as new modes. A second reason is that we have taken into account that most of the (re)locations of firms occur within the region of origin.

Secondly, what would this large scale implementation of ITS look like? And what can be said about the possible impact on attractiveness? How important are differences in penetration level? There fore we will briefly look at the theoretical differences in impact of these ITS concepts on (re)location of firms. Can we, for instance, explore differences in spatial dynamics between ITS in public transport and in car driving?

\section{ITS as a settlement factor}

Before discussing possible implementations and advantages of ITS systems, it is important to elaborate on a more systematic view of ITS. The notion of Intelligent Transportation Systems has been mentioned multiple times in this paper. 


\begin{tabular}{|c|c|c|}
\hline Subsystem & ITS functionality & Examples ITS application \\
\hline \multicolumn{3}{|l|}{ Organisation of society } \\
\hline Transport need market & $\begin{array}{l}\text { Systems for facilitating virtual } \\
\text { mobility }\end{array}$ & Electronic commerce; tele-working \\
\hline Freight and passengers & $\begin{array}{l}\text { Information supply on transport } \\
\text { services; booking services }\end{array}$ & $\begin{array}{l}\text { Park and ride information; public } \\
\text { transport services information }\end{array}$ \\
\hline Transport service market & Pre-trip planning support systems & Trip reservation \\
\hline & Systems for logistic optimisation & $\begin{array}{l}\text { Telecommunications for fleet } \\
\text { management } \\
\text { Trip matching systems }\end{array}$ \\
\hline Vehicles & $\begin{array}{l}\text { Smart Motor Technology } \\
\text { Driver support systems }\end{array}$ & $\begin{array}{l}\text { Crash recorders } \\
\text { ADAS }\end{array}$ \\
\hline Traffic flow market & $\begin{array}{l}\text { Dynamic traffic management } \\
\text { systems }\end{array}$ & $\begin{array}{l}\text { Dynamic route information screens } \\
\text { Electronic payment } \\
\text { Variable message signs }\end{array}$ \\
\hline Physical transport infrastructure & $\begin{array}{l}\text { Lane optimisation technology; } \\
\text { infrastructure status control } \\
\text { systems }\end{array}$ & $\begin{array}{l}\text { Dynamic lane configuration } \\
\text { adaptation } \\
\text { Deterioration detection }\end{array}$ \\
\hline
\end{tabular}

Table 2. Indicative relationship between transportation subsystems, ITS functionality and the variety of ITS applications (based on Van der Heijden \& Marchau, 2003: 26)

Generally, ITS can be described as systems consisting of electronics, communications or information processing used singly or integrated to improve the efficiency or safety of surface transportation' (Tindemans et al, 2003: 2). This notion encompasses a large variety of applications ${ }^{10}$. Marchau \& Van der Heijden $(2000 ; 2002 ; 2003)$ use a structured view of ITS services. They conceptualise the transport system by seven subsystems: four subsystems comprising the transport system's physical features (infrastructure, vehicles, goods or passengers and spatial and economic organisation) and three markets representing the interactions between the transport system's physical features. The three markets are the transport need market, the transport market and the traffic market.

Most gains in terms of safety, comfort and throughput in transportation networks is expected from technological developments within the field of driver support systems. These systems are called ADAS. However, these expectations are to a large extent dependent on future combinations of different ADAS applications and the integration of ADAS, ATIS and ATMS. An example of integration between ADAS is vehicles equipped with more than one ADAS

\footnotetext{
${ }^{10}$ For a more specific and complete overview on the nature of different ITS applications see for example publications by Ertico (e.g. 2002) and publications of Bishop (e.g. 2000).
}

application. Integration between subsystems occurs for example when ADAS systems use infrastructure to operate. Such integration could provide large gains in terms of safety, comfort and throughput in networks.

Examples of ADAS are Intelligent Speed Adaptation (ISA) and Adaptive Cruise Control (ACC). ISA is an in-car system that assists or controls a vehicles speed limit. If a car is equipped with ISA and enters an $80 \mathrm{~km} / \mathrm{u}$ road, the car, slows down and adjusts its speed to what is permitted, either by getting a signal from infrastructural devices or by using the digital map in the vehicle on which maximum posted speed have been pre-programmed. One can think of large safety potentials when ISA would be used at large scale. ACC is an intelligent cruise control system. It detects vehicles in front and back of the car and anticipates their speed. Instant breaking of a front car could warn the driver or intervene by slowing down the speed. Like ISA, ACC has large safety potentials. Further, ACC could increase driving comfort and road usage efficiency. ISA and ACC are two examples of ADAS systems. A final stage of ADAS development could result in for example fully automated driving. Although such a concept is not plausible to become reality on a large scale in the near future, its potentials are sufficient great to conduct much research on automated driving.

Similar to integration of different ADAS we expect large gains from new ITS 
concepts that combine applications from other user service bundles with ADAS. As table 2. shows these other services are mainly ATMS and ATIS. Contrary to the development of ADAS, ATMS and ATIS systems in transportation have largely matured (Bishop, 2000). These are for example systems that inform drivers or passengers about the trip. Examples of such systems are Variable Message Signs (VMS) and Personal Intelligent Travel Assistant (PITA). VMS systems inform drivers on motorways about congestion or incidents. Alternative routes are suggested. Although the benefits of such a system are not considered to be impressive, they do stimulate traffic in usage of variable roads. PITA is a GSM system that gives real-time route information to passengers on arrival and departure of different public transport. In case of delay, alternative route information is provided.

Thus, our image of the future is probably coloured by new ITS concepts that are constructed from ADAS and further surrounded by several other ATMS and ATIS user services. Those ITS concepts would influence several parts of the transportation network. There are two possible scenario's as to how ITS will affect land-use decisions.

Thus, future ITS concepts that have great potential and have reasonable chance of being developed would focus on ADAS plus ICTbased travel information and traffic management. Such a concept is our focus of research. We will name it ADAS+ from now on.

The development process of $A D A S+$ is difficult mainly because of large uncertainties within the technological development of ADAS and the market potential for ICTservices. With regard to ADAS for instance, the economic benefit of an automatic public bus system is potentially large. About three quarters of a bus companies' costs is spent on personnel. However, the automation of a bus system requires new technical and legal systems to insure passenger safety. More specific, the ITS applications that provide precise navigation need additional driver assistance systems. This requires extra political and financial investments. Given the fact that the implementation of such technological developments is expensive and municipalities face limited budgets a fixed strategy is needed. Therefore, municipalities are forced to choose to be selective in terms of the ITS strategy they prefer to accommodate. It is hardly possible to invest on ITS for the whole variety of transport activities. Consequently, these public actors can either support services regarding car driving, freight transportation, public transport or perhaps a low level of mixed services. ITS (in particular traffic flow control) has proven to be able to improve throughput in transportation networks (see e.g. Juan et al., 2003) and consequently to improve access to nearby locations.

\section{'Attractiveness' of ITS}

How can a possible influence of ITS be made more specific? In other words: how can ITS contribute to the attractiveness of a transportation system? To start on an extensive answer to this question we must focus on the core: infrastructural applications, in-vehicle applications and their combination. A distinction should be made to the level of technological support the system provides to the driver. This refers to the degree of driving automation by the system: Informative (auditive or visual signals to the driver, who has to decide what to do with the information), Assisting (system takes over some driving tasks, but intervention by the driver) and Autonomous (system takes over certain driving tasks, without intervention options for the driver). The tendency is to intensify $R \& D$ on assisting and autonomous systems. For example, in the Netherlands pilots with automated people movers and freight trucks have been initiated in recent years. The more attention for autonomous driving is intensifying, the more the link with the infrastructure system becomes important and the more the discussion on the transport services level and organisation is triggered.

The in-vehicle applications are linked to the basic driving tasks of the driver. These systems are ADAS. There are various ADAS under development. For instance, Intelligent Speed Adaptation, Lane keeping Assistance or Adaptive Cruise Control. Often a distinction is made in this respect between the drivers' controlling task (task associated with keeping the vehicle on the road), manoeuvring task (lateral and longitudinal vehicle positioning in relation to other vehicles) and the navigation task (route choices). 


\begin{tabular}{|c|c|c|c|c|}
\hline \multirow[t]{2}{*}{ System } & \multicolumn{4}{|c|}{ Impacts } \\
\hline & Safety & Comfort & Congestion & Environment \\
\hline $\begin{array}{l}\text { Adaptive Cruise Control } \\
\text { Lane Departure Waning }\end{array}$ & V V & V V & V & V \\
\hline Lane Keeping Assistance & V & V V & V & V \\
\hline Side-obstacle warning & V V & & & \\
\hline Intersection Collision Warning & V V & & & \\
\hline Parking Assistance & V V & V & & \\
\hline Forward Collision Warning & V V & & V & \\
\hline Night Vision Enhancement & V V & V & & \\
\hline Intelligent Speed Adaptation & V & V V & & V \\
\hline Fully Automated Driving & $\bar{V}$ & V V & V V V & V \\
\hline
\end{tabular}

Until recently, hardly any links between ADAS and infrastructure management were made. Increasingly however, thoughts and experiments focusing on the combination of in-car and infrastructure-based ITS applications are debated. These have for instance been described by Van der Heijden and Marchau (2002) in terms of different transport service levels.

These developments, that are hardly to be expected to become reality on a large scale in the next years, are important for the discussion on the long term relationship between transport and spatial development triggered in this paper. In more specific terms of attractiveness we refer for example to the first deliverable of project STARDUST, a European research programme. STARDUST aims to explore the field of ADAS and Automated Guided Vehicles (AGV).

In this, it distinguishes Adaptive Cruise Control (ACC), Lane Departure Warning, Side-Obstacle warning Systems, Forward Vehicle Collision Warning Systems, Intersection Collision Warning Systems, Parking Assistance, Night Vision enhancement Systems, Intelligent Speed Adaptation (ISA) and Full-automated Driving. These systems are under development in the USA, Europe (including Israel) and Japan. The former mentioned ADAS systems and Full-automated driving are dependent upon a large variety of smaller technological developments, in particular sensors (laser and wave radar), navigation and detection systems.

Table 3. shows the expected impact of different ADAS and AGV applications on safety, comfort, congestion and environment. The impact rates are expert expectations based on an extensive international literature study. Note that, as we mentioned previously, only Fully Automated Driving has a real strong impact on congestion. Next, Fully Automated Driving scores well on safety, comfort and environment. If we interpret attractiveness of ITS in terms of 'the number of persons/households per transportation system' as was described earlier in this paper Fully Automated Driving has high potential. And if we interpret attractiveness in terms of 'movement resistance' Fully Automated Driving has a strong impact on comfort and less impact on safety. Fully Automated Driving has the highest potential to increase what we called attractiveness of a transportation system. Looking at influences of ITS, this research will further solely aim at the influence of Fully Automated Driving. However, plausibility of implementation remains an important criterion. Hence, it is possible that some features of automation will not maintain our focus in research. Fully Automated Driving can be applied to freight transport, public transport and road traffic. Key technologies used are: dedicated lanes (e.g. CombiRoad and ULS projects in Netherlands), vehicle position technology (e.g. Parkshuttle projects in EC), obstacle detection, vehiclevehicle and vehicle-roadway communication and sensor technology for vehicle ranging (STARDUST, 2001).

Currently, Fully Automated Driving is only applied successfully in small public transport concepts. Expected is that within 5 to 10 years, Fully Automated Driving will be possible for freight transport and larger public transport systems. Implementing Automated Fully Driving in road traffic requires much 
more technological development regarding safety and new legislation by governments. Fully Automated Driving is an interesting concept to test whether location preferences will be influenced, at least theoretically.

Although Table 3. shows some promising impacts of AVG, we should remain cautious. Van Arem \& Smits (1998) show for example that impact of AVG on levels of mobility and travel time is much less attractive. Moreover, the impact is dependent upon multiple aspects. Differences result for instance from the role of government, the level of regulation regarding $\mathrm{AVG}$, implementation of dynamic traffic management (DTM), transportation mode and period of time.

Thus, it is expected that advanced levels of transport automation, based on the integration of ITS systems in infrastructure and in-car, such as Fully Automated Driving, require quite some investments in technological facilities and a dedicated organisation for operational management. Van Arem \& Smits (1998) discuss that 'although the study shows that $A V G$ can help solving mobility problems, it appears that AVG needs to be embedded in an integral transport policy [...]' (1998: 21). For example, sensor technology is required in each road network for real-time data-collection on traffic flows and incident management. Real-time, tailormade information should be available on various modalities for travellers; guiding autonomous driving vehicles might require Global Positioning System (GPS) and sensor facilities on dedicated roads. Particularly when investments in supporting technology and traffic flow management are infrastructurebased, it seems rather plausible that these investments will be selective initially (that is: initially not everywhere but related to certain pieces of the transport system). The first reason for that is that (mainly public) budgets, usually needed for infrastructure adaptations, are limited. Of course extra budgets might be realised by charging transport users for improved transport service quality but there willingness to pay is uncertain. Secondly, not all infrastructures will be candidate for these applications, but selected parts of road networks will be, because traffic problems (e.g. congestion level, safety level) are not the same in all parts of the network and the contribution to the total performance improvement will be a serious criterion for investment. Thirdly, it is plausible that such an infrastructure transition program will be phased in time: new investments will be based on the evaluation on the impacts of former investments (effectiveness, the need for changing the concept): the evolutionary innovation process ${ }^{11}$. And as we argued before municipalities play an important role in location supply and the development of new transportation systems.

To indicate a plausible development of these ITS concepts, one can think of selective promotion by public policies of certain target groups, for instance public transport, business cars or urban freight transport. This might lead to investments in for example all the facilities accommodating high quality public transport, including dedicated lanes, automated vehicles, and full information supply for travellers. Argiolu (2002) has described experiments with such ITS-based approaches in the Dutch cities of Eindhoven and Rotterdam/Capelle aan den IJssel. For freight transport a full automated concept was already seriously studied (CTT, 1995-1997). Serious thoughts for applying such a freight transport technology in the Dutch urban agglomeration of EnschedeHengelo are currently under study. A final possibility to be mentioned is to invest in the facilities required for multi-modal chain mobility, linking the car system systematically with public transport facilities. A strong focus may be laid in that context on the performance of the transfer points. Both options will lead to the investments in smart and partly dedicated, pieces of infrastructure within the urban agglomeration.

Considering these plausible future ITS developments, we can assume that the implementation of ITS will follow a pattern of selective adaptation (based on geographical and functional considerations) of the transportation system. Given the pursued goals of ITS (improving safety, throughput in networks and travel comfort) it is assumed to generate competitive advantages for these parts of the transportation network from the perspective of transport performance and attractiveness for travellers.

\footnotetext{
${ }^{11}$ For an in-depth discussion on technological development as a process, see e.g. Giovanni Dosi (1982) on 'Technological paradigms and technological trajectories'.
} 
For example, a dedicated lane for full automated driving inbound a metropolitan area with guaranteed travel time and parking place at the destination might turn out to be more attractive, irrespective the need for reservation of an individual access slot and the need for extra payment for the service, than to accept the present daily peak congestion and uncertainty of finding a parking place.

\section{Methodological framework}

Hypothetically, ITS can contribute to the attractiveness of a location. As a consequence, it gains influence on future settlementconsiderations. This influences actors that are involved in the development of firm location, whilst making spatial choices. Since ITS are state of the art in transportation and only few data is available, the methodological approach to test the hypothesis is explorative from nature (see figure 1. on the next page). A method that is commonly used to explore future situations is scenario-building.

Scenarios can be used for several reasons ${ }^{12}$. A general motive to use scenarios is to support decision-making by reducing uncertainties. In this project they serve as a tool to gain more insight in possibilities of future ITS concepts. To use scenarios effectively ${ }^{13}$ in this research we need to restrict the number of scenarios. Both the number and emphasis of scenarios can be determined by a procedure that uses morphological analysis ${ }^{1415}$. The first step in this procedure involves the construction and initial exploration of alternative ITS concepts for the future. These ITS concepts are constructed by adding traffic and travel management services to ADAS. The main purpose of this step is to structure and limit the set of alternative ADAS+ concepts. The morphology of the scenario space is constructed by the appropriate value ranges of

\footnotetext{
${ }^{12}$ For an updated scenario typology see e.g. Van Notten et al. (2003)

${ }^{13}$ For more information on how to develop and use scenarios in research, see for example Schnaars (1987)

${ }^{14}$ For a more detailed description on the nature of the morphological analysis see Van Doorn \& Van Vught (1978)

${ }^{15}$ For an example of the use of the morphological analysis see Marchau (2000)
}

the dimensions. This morphology defines the maximum number of possible scenarios (Porter et al., 1991). At first we identify basic dimensions constituting the variety of concepts. Secondly, we specify the values of these dimensions and finally we evaluate all possible combinations of these values. The unique combinations of possible values along the different features produce a variety of alternative concepts. Next, these concepts are evaluated to prune highly unlikely or unfeasible concepts. This involves, for instance, concepts that are unlikely to contribute to general transportation goals and/or concepts that are unfeasible from technical and/or societal point of view. The elimination of these concepts will lead towards the scenario narratives.

The problem then is to identify those ITS scenarios that will be relevant in meeting the goals of the foresight. That is, which ITS can contribute to the attractiveness of a location? These final steps in limiting the scenarios will be based on features of ITS concepts that have been implemented already combined with the results of research, which have been described in literature.

The outline for the validation of the scenarios is based on expert opinion. Policymakers, scientists and companies involved in the development of ITS criticise and re-shape the scenarios. This expert data collection could for example be performed using a Delphi technique ${ }^{16}$, in which consensus about for example feasibility of the different scenarios, is gained by repeating several rounds of judgement. Other ways to collect the date are for instance workshops or by using group model building tools.

\footnotetext{
${ }^{16}$ For an example on the usage of the Delphi method to define the future of AVG see Marchau 2000 .
} 


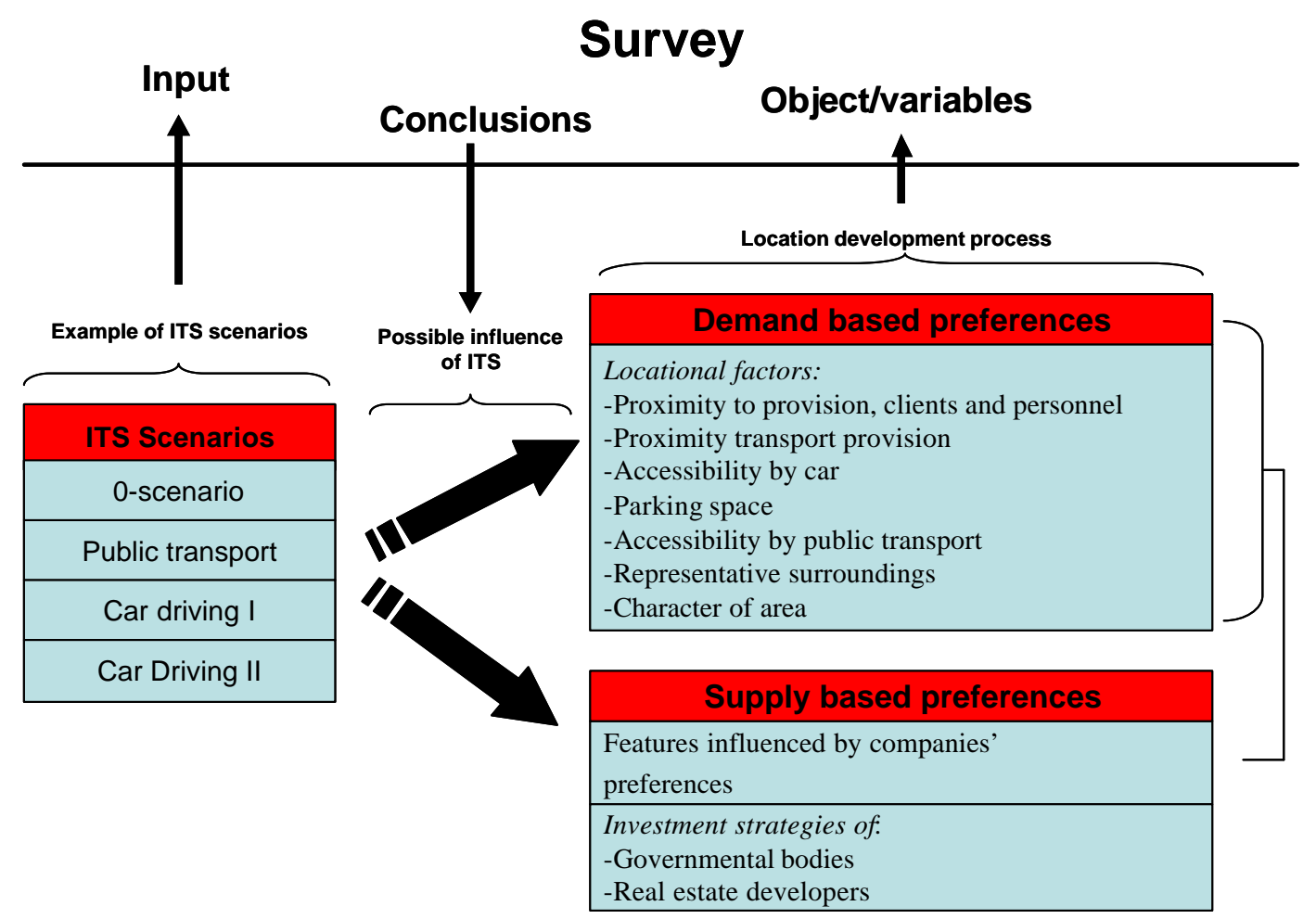

Figure 1. Theoretical and methodological concept.

The construction and validation of the scenarios result in narratives and/or images of different ITS implementations in an urban region. An important step from construction to narrative is to translate the scenarios from the sophisticated approach that safeguards plausibility to narratives or images that are useful in survey research. Thus, they should be appealing enough to make sense to actors involved in development process of companies. This conversion could for instance be conducted by using a Geographical Information System (GIS).

Dependent variable in the survey research would be the preferences of relevant actors regarding firm locations. The specific contents of the questions are not defined yet. The aim of the survey is to unfold the possible influence of ITS on the preferences of firm location in an urban region ${ }^{17}$, for which the

\footnotetext{
${ }^{17}$ The spatial scale of the region as an entity seems well suited for such a scenario since it covers most of the urban areas on which transport problems occur and thus municipalities or regions will invest in. Pellenbarg (1996) found that $57 \%$ of the companies movements stay within the municipality and $97 \%$ within the province in 1992. Bok et al. (2003) found that the share of firms in the dataset who migrate within the boundaries of their
}

scenarios $^{18}$ form the basis. The sampling of respondents should take relevant subpopulations into account.

At least, this means that samples are taken from both actors involved in the demand side, companies, and the actors involved in the supply side of the location development process. Possibly further differentiation between subgroups is needed.

Eventually, we need to reckon for the fact that the differences between scenarios might also trigger different subgroups. An important issue in research for example s the connection between plausible ADAS+ conceptualisation and its specific impact on location preferences. As we argued earlier, the type of transport which this ADAS integration would apply to differentiates strongly with the type of preference actors have. What if we regard table 1. and link this with a concept

municipality is $75 \%$ and original COROP-region (COROP=Dutch statistical spatial entities) is $97 \%$. The Netherlands consist of 43 COROP regions. Example: Dutch cities of Arnhem and Nijmegen are one COROP.

${ }^{18}$ For an elaboration on the specific contents of the ITS scenarios as they are constructed in this research project see Argiolu et al. (2004, forthcoming) 
such as Fully Automated Driving? Applied to public transport it would probably only appeal to firms regarded as 'stationeries' and 'classicists'. Besides, in such a case it is expected that municipalities will play a more important role in pinpointing location development than in case of regional roadway development. Finally, if we want to draw conclusions on possible impact on spatial development in the future we also need to take into account the penetration level. Fully Automated Driving within a public transport system probably has a smaller penetration level than in case of Fully Automated Driving on highways.

\section{Conclusion}

Geographical differences in ITS-based accessibility might result in changes in location patterns. It has been argued that location choices of businesses and actors in the supply side are to a significant degree sensible for perceived differences in accessibility, either in terms of the travel costs (time, money) or in terms of distance. A next step in reasoning is that these differences in accessibility at a certain moment might lead to gradually changing location choice behaviour of businesses and commuters. These choices will be characterised by a preference for locations that are better accessible by ITS-based transport services as compared to locations that are not. Measured in terms of a long periods (decades), we expect a geographical pattern of (at least certain) business activities that increasingly will match with the geographical pattern of high level ITS applications.

To test the research hypothesis two main studies will be done. The first is a scenario study to specify the combinations of ITS applications that would increase location attractiveness. The second will be a survey among actors that influence spatial development. These are 'so-called' demanders and suppliers of locations. Comparable studies (see e.g. Tayyaran et al., 2003; Tayyaran \& Khan, 2003) show that the proposed methodology can be fruitful in answering questions on impact of IT and ITS on location choice. Their results show that for residing '[...] telecommunicating and ITS measures are highly significant factors in the residential choice model' (Tayyaran et al., 2003: 171).
Clearly many operational decisions have to be taken for performing these substudies. A variety of issues has been mentioned already. Important is that by exploring the issue in this paper, and the first attempts to translate them into researchable questions, we made an important step for more systematically studying a challenging issue to link technological innovation and spatial development. Evidently, we will report on the progress in future.

\section{Acknowledgements}

The research project that is described in this paper is carried out as part of the NWOCONNEKT Research program "Behavioural Analysis and Modelling for the Design and Implementation of Advanced Driver Assistance Systems" (BAMADAS). Our project is sponsored by the Cornelis Lely Foundation.

Helpful comments on earlier drafts of this paper by Edwin Buitelaar and Erik Louw are gratefully acknowledged. However, only the authors are accountable for any remaining errors and omissions. 


\section{References}

ALVESSON, M \& K. SKÖLDBERG (2000) Reflexive Methodology, New Vistas for Qualitative Research, SAGE, London

ARGIOLU, R., (2002) Innovatief openbaar vervoer. Anders of Beter?, master thesis spatial planning, Nijmegen School of Management, University of Nijmegen (In Dutch)

ARGIOLU, R., R. VAN DER HEIJDEN \& V. MARHCAU (FORTHCOMING) Looking at ITS in the future: four scenarios, paper to be presented at the WCTR Istanbul, 4-8 July, Turkey

ATZEMA, O. \& E. WEVER (1994) De Nederlandse Industrie, Ontwikkeling, spreiding en uitdaging, Van Gorcum Assen (In Dutch)

BANISTER, D. (ed.) (1995) Transport and urban development, E \& FN SPON, London

BISHOP, R. (2000) A survey of Intelligent Vehicle Applications Worldwide, Richard Bishop Consulting USA

BOK, M., B. BLIJE \& F. SANDERS (2003) The influence of the transportation system on land use: A disaggregated analysis of the migration patterns of firms on the office market and the accessibility of locations, paper for Colloquium Vervoerplanologisch Speurwerk 2003, Netherlands

CTT (1994-1996) Combiroads reports, Center for transport Technology, Rotterdam

DOSI, G. (1982) Technological paradigms and technological trajectories, Research Policy, 11, pp. $147-162$

EDWARDS, M. \& R. MACKETT (1996) Developing new urban public transport systems, Transport Policy, Vol. 3, No. 4, pp. 225-239

ERTICO (2002) Intelligent Transport Systems and Services, ITS - Part of Everyone's Daily Life, ERTICO - ITS Europe \& Navigation Technologies, Brussels

FOURTH REPORT ON PHYSICAL PLANNING EXTRA (1991) Ministry for Housing, Physical Planning and Environment, Sdu. The Hague (In Dutch)

FILARSKI, R. (1999) The rise and fall of transport systems: technology, human behaviour, mobility and spatial factors. Paper presented at the NECTAR conference, 20-23 October 1999 in Delft.
GEURS, K. \& RITSEMA VAN ECK (2001) Accessibility measures Review and applications, Research for men and environment (RIVM), Bilthoven, The Netherlands.

HAKKESTEEGT, P. (1986) Vervoerssytemen- en modellen. Deel A: Vervoerkunde. Delft: Vakgroep Verkeer, Faculteit der Civiele Techniek, TU-Delft. (In Dutch)

HAKKESTEEGT, P. (1991) Vervoersystemen en modellen. Deel A: Algemene Vervoer- en Verkeerskunde. Delft: Vakgroep Verkeer, Faculteit der Civiele Techniek. TU-Delft (In Dutch)

HEGEMAN, G. (Forthcoming) Effect advanced driver assistance systems on overtaking on two-lane roads, Paper to be presented at IEEE conference Den Haag, The Netherlands, 2004

HOTELING, H. (1929) Stability in competition, The economic journal, 39, pp. 41-57

JUAN, Z., J. WU \& M. McDONALD (2003) The socio-economic impacts assessment of advanced convoy driving on motorway, Transportation Research Part A, 37, pp. 731-747

KRABBEN, VAN DER E. \& J. LAMBOOY (1993) A theoretical framework for the functioning of the Dutch property market, Urban Studies, 30, no 8, pp. 1381-1397

LAMBOOY, J., E. WEVER \& O. ATZEMA (1997) Ruimtelijke economische dynamiek, Uitgeverij Coutinho B.V., Bussum, The Netherlands (In Dutch)

LUKKES, P., A. KRIST \& P. VAN STEEN (1987) Kantorenmarkt Investeren en Ruimte, Vonk Uitgevers, Zeist (In Dutch)

LOUW, E. (1996) Kantoorgebouw en Vestigingplaats, een geografisch onderzoek naar de rol van huisvesting bij locatiebeslissingen van kantoorhoudende organisaties, Stedelijke en Regionale Verkenningen 12, Delftse Universitaire Pers (In Dutch)

LOUW, E. E. VAN DER KRABBEN \& H. PRIEMUS (2003) Spatial development policy: changing roles for local and regional authorities in the Netherlands, Land use policy, Vol. 20, pp. 357366

MARCHAU, V. \& R. VAN DER HEIJDEN (1998) Policy aspects of driver support systems implementation: results of an international Delphi study, Transport Policy, Vol. 5, no 4, pp. 249-258 
MARHCAU, V. (2000) Technology Assessment of Automated Vehicle Guidance: Prospects for automated driving implementation. Delft University Press: Delft.

MARCHAU, V. \& R. VAN DER HEIJDEN (2003) Innovative Methodologies for Exploring the Future of Automated Vehicle Guidance, Journal of Forecasting, Vol. 22, pp. 257-276

MARCHAU, V., R. VAN DER HEIJDEN \& W. VREE (2000) Strategische Ontwikkelingen rond Verkeersbeheersing, De rol van ITS, Faculty of Technology, Policy and Management, Delft University of Technology (In Dutch)

MUILERMAN, G.J. (2001) Time-based logistics, Delft University Press, Delft, The Netherlands

PARSONS, W. (1999) An Introduction to the Theory and Practice of Policy Analysis, Edward Elger, Cheltenham, United Kingdom

PELLENBARG (1996) 'Struktuur en ontwikkeling van bedrijfsmigratie in Nederland', Planning, Vol. 48., INRO-TNO, Delft, pp. 22-32 (In Dutch)

PELLENBARG, P., L. VAN WISSEN, J. VAN DIJK (2002) Firm relocation: state of the art and research prospects: SOM Research Report 02D31, University of Groningen

PEN, C.J. (2002) Wat beweegt bedrijven? Besluitvormingsprocessen bij verplaatste bedrijven, Netherlands Geographical Studies, 297, Groningen (In Dutch)

PORTER, A., A. ROPER, T. MASON, F. ROSSINI \& J. BANKS (1991) Forecasting and Management of Technology. John Wiley \& Sons Inc., New York

RUNHAAR, H. (2002) Freight transport at any price? Delft University Press, Delft, The Netherlands

SIMON, H.A. (1957) Models of a man: social and rational, John Wiley New York

SIMON, H.A. (1960) The new science of management decision. New York: Harper \& Row

STARDUST (2001) Deliverable 1, Critical Analysis of ADAS/AVG options to 2010, selection of options to be investigated, European Commission Fifth Framework Programme, Energy Environment ad Sustainable Development Programme
TAYYARAN, M. \& A. KHAN (2003) The effects of Telecommuting and Intelligent Transportation Systems on Urban Development, Journal of Urban Technology, Vol. 10, No. 2, pp. 87-100

TAYYARAN, M., A. KHAN \& D. ANDERSON (2003) Impact of telecommuting and intelligent transportation systems on residential location choice, Transportation Planning and Technology, Vol. 26, No. 2, pp. 171-193

THÜNEN, J. VON (1826), Der isolierte Staat in Beziehung auf Landwirtschaft und Nationalökonomie, Zweite auflage (1842) (Reproduction in 1921, Jena: Gustav Fischer Verlag).

SCHNAARS, S. (1987) How to Develop and Use Scenarios, Long Range Planning, Vol. 20, No.1, pp. 105-114

VAN AREM, B. \& C. SMITS (1998) An exploration of the development of Automated Vehicle Guidance Systems, TNO-report Inro/VVG 1997-3, TNO Inro, Delft

VAN DOORN \& VAN VUGHT (1978) Forecasting: Methoden en technieken voor toekomstonderzoek. Van Gorcum, Assen. (in Dutch)

VAN DER HEIJDEN, R. \& V. MARCHAU (2002) Innovating road traffic management by ITS: a future perspective', Int. J. Technology, Policy and Management, Vol. 2, № ${ }^{\mathrm{o}}$, pp. 20-39

VAN DER HEIJDEN, R. \& K. VAN WEES (2001): Introducing advanced driver assistance systems: some legal issues, European Journal of Transport and Infrastructure Research, vol. 1, pp. 309-326

VAN NOTTEN, P., J. ROTMANS, M. VAN ASSELT \& D. ROTHMAN (2003) An updated scenario typology, Futures, 35, pp.423-443

WEBER, A. (1909) Ueber den Standort der Industrien, Ersten Teil: Reine Theorie des Standorts (Zweite auflage (1922)), Tübingen: J.C.B. Mohr Verlag 